\title{
Papel da imunofenotipagem por citometria de fluxo no diagnóstico diferencial das pancitopenias e das linfocitoses
}

The role of flow cytometer-based immunophenotyping in the differential diagnosis of pancytopenia and of lymphocytosis

Eduardo M. Rego ${ }^{1}$

Guilherme A. S. Santos ${ }^{2}$

\begin{abstract}
A imunofenotipagem por citometria de fluxo (CMF) é atualmente uma ferramenta indispensável para o diagnóstico hematopatológico. Nos últimos anos muitos progressos foram alcançados em instrumentação, novos anticorpos e fluorocromos e programas de análise. Consequentemente, houve um grande avanço no conhecimento da patogênese das neoplasias hematológicas e novos marcadores diagnósticos e prognósticos foram descritos. Revisamos aqui a contribuição destas novas técnicas no diagnóstico diferencial de pacientes com bi- ou pancitopenia e linfocitose. São apresentados os achados mais frequentes e as dificuldades na interpretação dos resultados. Além disto, a importância do uso concomitante de um conjunto de outras técnicas diagnósticas é demonstrada. Rev. Bras. Hematol. Hemoter.
\end{abstract}

Palavras-chave: Imunofenotipagem; pancitopenia; linfocitose; citometria.

\section{Introdução}

Tradicionalmente, o diagnóstigo hematopatológico é dependente de uma combinação de análise citomorfológica e histológica. ${ }^{1}$ No entanto, técnicas de imunofenotipagem como a citometria de fluxo e a imuno-histoquímica (IHQ) revelam informações relevantes ao diagnóstico, como o estágio de maturação das populações celulares analisadas, a presença de células com fenótipo significativamente anormal, além de avaliar a presença de marcadores associados ao prognóstico ou até mesmo marcadores que são alvos terapêuticos. ${ }^{2}$ Vantagens e desvantagens da CMF como método de imunofenotipagem são listadas na Tabela 1 .

A classificação da Organização Mundial de Saúde (OMS) dos tumores dos tecidos hematopoético e linfoide preconiza uma abordagem diagnóstica com ênfase nos se- guintes parâmetros: morfológico, fenotípico e genotípico. ${ }^{3}$ No entanto, não é necessário e tão pouco favorável do ponto de vista custo-benefício realizar múltiplos testes em todas as amostras. ${ }^{2}$ Então, em quais situações clínicas está indicado proceder com a citometria de fluxo? Em 2006, um grupo internacional de especialistas reuniu-se em Bethesda, nos EUA, a fim de formular um consenso de recomendações para a análise imunofenotípica de neoplasias hematológicas. A Tabela 2 apresenta as recomendações do Consenso Internacional de Bethesda 2006 quanto às indicações médicas de proceder com a CMF. ${ }^{4}$

Esta revisão procurará focar na avaliação dos aspectos mais relevantes da imunofenotipagem por citometria de fluxo no diagnóstico hematopatológico. Das indicações listadas pelo consenso de Bethesda ${ }^{4}$ serão abordadas a bicitopenia e pancitopenia, e a linfocitose.

\footnotetext{
${ }^{l}$ Médico. Livre-docente pela FMRP-USP. Professor Associado da Faculdade de Medicina de Ribeirão Preto.

Diretor Científico da Fundação Hemocentro de Ribeirão Preto-SP.

${ }^{2}$ Médico. Professor Assistente da Faculdade de Medicina da Universidade de Ribeirão Preto - Unaerp - Ribeirão Preto-SP.

Divisão de Hematologia do Departamento de Clínica Médica da Faculdade de Medicina de Ribeirão Preto - Universidade de São Paulo.
}

Correspondência: Eduardo M Rego

Av. Bandeirantes, 3900

14048-900 - Ribeirão Preto-SP - Brasil

Tel: (55 16) 36022-888 - Fax: (55 16) 3633-6695

E-mail:emrego@hcrp.fmrp.usp.br

Doi: 
Tabela 1. Vantagens e desvantagens da citometria de fluxo como método de imunofenotipagem

\begin{tabular}{|c|c|}
\hline Vantagens & Desvantagens \\
\hline $\begin{array}{l}\text { Método semi-automatizado que permite avaliar milhares de } \\
\text { células por amostra }\end{array}$ & $\begin{array}{l}\text { Condições patológicas que levam a uma medula óssea esclerótica ou } \\
\text { hipercelular com empacotamento }\end{array}$ \\
\hline $\begin{array}{l}\text { Apresenta menor variabilidade dependente de operador quando } \\
\text { comparada à análise morfológica }\end{array}$ & $\begin{array}{l}\text { Perda das relações de arquitetura da medula óssea ou outro espécime } \\
\text { utilizado }\end{array}$ \\
\hline $\begin{array}{l}\text { Informações diversas de cada célula como tamanho, } \\
\text { complexidade do citoplasma e imunofenótipo podem ser } \\
\text { obtidas }\end{array}$ & $\begin{array}{l}\text { Nem sempre populações aberrantes do ponto de vista de imunofenótipo } \\
\text { indicam malignidade }\end{array}$ \\
\hline $\begin{array}{l}\text { Método robusto para a imunofenotipagem de populações } \\
\text { celulares normais ou patológicas }\end{array}$ & $\begin{array}{l}\text { Linfomas de células T que não apresentam aberrância de imunofenótipo } \\
\text { não podem ser detectados }\end{array}$ \\
\hline Biópsia tecidual pode ser evitada em casos selecionados & Possivel falso negativo no envolvimento focal da medula óssea por linfoma \\
\hline
\end{tabular}

Tabela 2. Recomendações do Consenso internacional de Bethesda de 2006 quanto às indicações médicas em proceder com a citometria de fluxo (CMF)

\begin{tabular}{lc}
\multicolumn{1}{c}{ CMF indicada } & CMF não indicada \\
\hline Bicitopenia e pancitopenia & Neutrofilia \\
Linfocitose & $\begin{array}{c}\text { Hipergamaglobulinemia } \\
\text { policlonal } \\
\text { Ponocitose }\end{array}$ \\
Eosinofilia & Trombocitemia, \\
Blastos no sangue periférico, medula \\
óssea ou liquidos corporais \\
Plasmocitose ou gamopatia monoclonal
\end{tabular}

\section{Imunofenotipagem por Citometria de fluxo (CMF) em condições associadas à bicitopenia ou pancitopenia}

\section{Leucemias agudas}

Na imunofenotipagem por CMF, um diagrama de SSC (desvio lateral da luz) x CD45 é habitualmente empregado para a identificação inicial dos blastos visto que estas células possuem baixa intensidade de expressão de CD45 e SSC baixo.

Blastos diferem de células mais maduras por expressarem marcadores de imaturidade e não expressarem marcadores associados à maturação celular. Por exemplo, mieloblastos podem ser distinguidos de células mieloides em maturação por apresentarem marcadores de imaturidade como CD117, CD34 e ausência de marcadores de maturação como CD11b, $\mathrm{CD} 15$ e CD16. ${ }^{2}$

O método clássico para estimar o porcentual de blastos é a microscopia (mielograma), embora, por analisar milhares de células, a CMF seja um método muito preciso em estimar o porcentual de células imaturas na amostra. No entanto, limitações inerentes ao procedimento de coleta podem prejudicar a interpretação dos resultados e pode haver grandes inconsistências se os métodos forem comparados para este fim. As amostras enviadas à CMF frequentemente contêm me- nos espículas ósseas e são mais diluídas com sangue periférico quando comparadas às amostras usadas para preparar a distensão da microscopia (mielograma). Por outro lado, o denominador usado para determinar a porcentagem de blastos é diferente entre os métodos. Nas contagens por microscopia, o denominador são as células nucleadas, e, na CMF, são todas as células analisadas, sendo que, usualmente, antes da imunofenotipagem é feita a lise de eritrócitos, o que leva à lise variável de eritroblastos. ${ }^{1}$ Devido a estas limitações, a microscopia ainda representa o método de escolha nos dias de hoje para a contagem de blastos. Porém, é importante salientar que sempre que o mielograma não estabelece o diagnóstico de leucemia aguda na situação de pancitopenia não é possível partir da premissa que o material é adequado. Situações relativamente frequentes na vigência de pancitopenia em que tanto o mielograma quanto a CMF não avaliam adequadamente o porcentual de blastos são uma medula óssea fibrótica ou liposubstituída. ${ }^{5}$ Nessas situações, a biópsia de medula óssea é o único procedimento diagnóstico adequado.

Muito mais do que a enumeração dos blastos, a identificação fenotípica destas células por CMF apresenta um papel central no diagnóstico das doenças blásticas. O estabelecimento da CMF para diferenciar leucemia linfoblástica aguda (LLA) de leucemia mieloide aguda (LMA) e definir a terapêutica apropriada representou um grande avanço no diagnóstico por ser um método bastante reprodutível para este fim específico. Marcadores mieloides expressos na LMA: mieloperoxidase (MPO), CD33 e CD13. Marcadores de célula T expressos em LLA-T: CD3 citoplasmático ou superfície, CD7. Marcadores de célula B expressos na LLA-B: CD19, CD22, CD79a. A positividade para o CD117 é um achado importante devido à sua especificidade no contexto de leucemia aguda, visto que é apenas expresso na LMA. ${ }^{6}$ É preciso lembrar que a CMF não substitui as reações de citoquímica realizadas com as amostras do mielograma, como a reação de peroxidase e estearase especialmente no objetivo de caracterizar o estágio de maturação das LMAs. No entanto, a CMF define o subtipo LMA-M0, que requer a expressão de marcadores mieloides como CD13 e CD33, doença não diagnosticada por citoquímica convencional, ${ }^{3}$ e colabora de 
Tabela 3. Sistema de pontuação para diagnóstico de leucemia bifenotipica. A obtenção de 2 ou mais pontos para duas linhagens diferentes qualifica o caso como leucemia aguda bifenotípica

\begin{tabular}{|c|c|c|c|}
\hline \multirow{2}{*}{ Pontos } & \multicolumn{3}{|c|}{ Linhagem celular } \\
\hline & Linfoide B & Linfoide $T$ & Mieloide \\
\hline 2 & CD22 & cCD3 & MPO* \\
\hline 1 & $\begin{array}{l}\text { CD10 } \\
\text { CD19 }\end{array}$ & $\begin{array}{l}\text { CD2 } \\
\text { CD5 }\end{array}$ & $\begin{array}{l}\text { CD13 } \\
\text { CD33 }\end{array}$ \\
\hline 0,5 & $\mathrm{TdT}$ & $\begin{array}{l}\text { CD7 } \\
\text { TdT }\end{array}$ & $\begin{array}{l}\text { CD14/CD15 } \\
\text { CD11b/CD11c }\end{array}$ \\
\hline
\end{tabular}

* A demonstração da atividade de mieloperoxidase (MPO) pode ser feita com qualquer método. Esta tabela é uma reprodução autorizada pelo autor, de "Hematologia: Fundamentos e Prática." Capítulo 42. Autor: Falcão RP.

forma central para o diagnóstico de LMA megacariocítica com expressão de CD61, CD41 e CD42b, doença de difícil diagnóstico diferencial com a LLA da infância. ${ }^{1}$

A CMF é de utilidade para diagnosticar leucemias agudas bifenotípicas e bilinhagem, doenças de prognóstico reservado. Alguns marcadores específicos de determinada linhagem na hematopoese normal são expressos de maneira aberrante nas leucemias agudas sem, no entanto, configurar leucemia bifenotípica. A Tabela 3 apresenta os achados compatíveis com doença bifenotípica e os achados apenas de aberrância fenotípica. Porém, é necessário lembrar que o diagnóstico das doenças blásticas, especialmente quando ocorre expressão de antígenos de mais de uma linhagem, precisa compreender uma abordagem com múltiplas técnicas diagnósticas que incluem, além da $\mathrm{CMF}$, a citogenética, morfologia e citoquímica.

O exame de citogenética apresenta papel importante no diagnóstico, classificação e estabelecimento do prognóstico das leucemias agudas. ${ }^{3}$ Alguns fenótipos de LMA estão associados com alterações citogenéticas recorrentes, como é o caso da LMA com t(8;21)(q22;q22) que, com frequência, apresenta expressão anômala de CD19 e CD56 e menos frequentemente TDT. A leucemia promielocítica aguda (LPA) com $\mathrm{t}(15 ; 17)(\mathrm{q} 22 ; \mathrm{q} 12)$ frequentemente apresenta o seguinte fenótipo: CD34 e HLA-DR negativos ou parcialmente positivos, CD11-b negativo, CD13 heterogêneo e CD117 e CD33 positivos. ${ }^{2}$ Embora a imunofenotipagem por CMF possa ser usada como uma ferramenta de investigação inicial, o método carece de sensibilidade e especificidade para a detecção de anormalidades citogenéticas recorrentes. ${ }^{7}$

A determinação de fenótipos aberrantes por CMF constitui-se em estratégia importante para o seguimento e detecção de doença residual mínima (DRM). Avanços consideráveis na instrumentação e no processamento dos dados permitiram que os laboratórios clínicos de CMF aumentassem significativamente o número de eventos adquiridos nas amostras. Atualmente é possível adquirir 500.000 ou 1 milhão de eventos com quatro ou mais cores levando o ensaio a ser sensível o suficiente para detectar um evento específico em 10.000 células. ${ }^{8} \mathrm{O}$ método está bem estabelecido para a pesquisa de DRM na LLA da infância, com estudos demonstrando que a presença de DRM é um marcador independente de pior prognóstico. ${ }^{9} \mathrm{Na}$ LMA, a pesquisa de DRM por CMF, embora ainda menos estabelecida do que na LLA, também tem o seu papel no seguimento, especialmente nos casos não associados às anormalidades citogenéticas recorrentes. A presente revisão não objetiva aprofundar o tema da DRM e os leitores que desejarem encontrarão boas revisões. ${ }^{10-12}$

\section{Tricoleucemia}

A tricoleucemia é uma doença linfoproliferativa de células B de comportamento indolente que afeta preponderantemente homens de meia idade. Os pacientes apresentam, em sua maioria, os seguintes achados: pancitopenia, esplenomegalia e pequena quantidade de células típicas circulantes (células pilosas). ${ }^{13}$ Com frequência as células apresentam características morfológicas, citoquímicas e imunofenotípicas específicas da doença. ${ }^{14}$ A morfologia é característica: o tamanho é de uma a duas vezes o do linfócito, o citoplasma tem volume variável, a membrana citoplasmática é irregular e apresenta projeções citoplásmicas finas, que lembram fios de cabelo; o núcleo é geralmente excêntrico e o nucléolo está ausente. ${ }^{15}$ Comumente não é possível aspirar a medula óssea (punção aspirativa seca ou dry tap). Nestes casos, a biópsia de medula óssea é essencial para o diagnóstico. Os principais diagnósticos diferenciais são o linfoma esplênico de células vilosas (LECV) e a tricoleucemia variante.

Em um contexto clínico apropriado, a visualização de células pilosas características em distensões de sangue periférico ou no mielograma e a positividade das células neoplásicas para a reação de fosfatase ácida resistente ao tartarato constituem o eixo central do diagnóstico da tricoleucemia. A biópsia de medula óssea (BMO) hipercelular e com infiltrado difuso ou focal de células mononucleares com citoplasma abundante (células espaçadas) e aumento de fibras de reticulina é um achado confirmatório, porém, a BMO pode ser hipocelular com infiltrados intersticiais. A CMF realizada no sangue periférico ou no aspirado de medula óssea apresenta papel confirmatório. ${ }^{15}$

O desenvolvimento das novas técnicas de CMF permitiu a detecção de eventos raros, como a presença de células pilosas no sangue periférico (usualmente menos que $0,5 \%$ ). ${ }^{16}$ Em um diagrama de CD45 versus $\mathrm{SSC}$, as células pilosas normalmente ocupam a região dos monócitos, células que estão ausentes ou muito diminuídas na tricoleucemia. Portanto, o achado de linfócitos monoclonais na "gate" habitualmente ocupada por monócitos constitui um achado que demanda a pesquisa de antígenos específicos. ${ }^{17}$ As células apresentam positividade para marcadores de linhagem B, com forte expressão de CD20, CD22 e imunoglobulina de superfície (IgSm) com componente de cadeia leve monoclonal (ou kappa ou lambda). Casos ocasionais podem ser negativos para IgSm. 
Raramente expressam CD5 e, em aproximadamente 10\% dos casos, podem expressar CD10. ${ }^{18}$

Três marcadores são particularmente úteis no diagnóstico de tricoleucemia. As células pilosas apresentam forte expressão de CD11c e quase sempre são positivas para CD25 e CD103. ${ }^{19} \mathrm{O}$ LECV e a tricoleucemia variante praticamente nunca apresentam coexpressão desses três antígenos. ${ }^{20}$

\section{Síndrome Mielodisplásica}

Tradicionalmente, a CMF tem sido considerada sem utilidade no diagnóstico de SMD. No entanto, estabelecer esse diagnóstico na ausência de displasia acentuada, sideroblastos em anel ou aberrações cromossômicas pode não ser uma tarefa simples. Recentemente, uma conferência internacional de especialistas no tema sugeriu a inclusão da CMF na abordagem diagnóstica destes casos. ${ }^{21}$ A expressão de CD7 e CD56 nos blastos de pacientes portadores dos subtipos anemia refratária (AR) e AR com sideroblastos em anel configurou pior prognóstico e tendência à dependência transfusional e evolução para LMA. ${ }^{22}$

\section{Detecção de células com fenótipo tipo Hemoglobinúria Paroxística Noturna (HPN)}

A detecção por CMF de neutrófilos e eritrócitos com deficiência em antígenos ancorados por glicosilfosfatidilinositol, como o CD55 e o CD59, ou ainda o CD16 e CD66, tornou-se padrão ouro para o diagnóstico de HPN. No entanto, com o avanço nas técnicas de CMF mais sensíveis, aumento de células com esse fenótipo (tipo HPN) tem sido detectado na SMD e na anemia aplásica, embora habitualmente correspondendo a menos que $1 \%$ dos granulócitos ou dos eritrócitos. ${ }^{2}$

Na HPN, a porcentagem de células com fenótipo característico está relacionada com as manifestações clínicas da doença. Pacientes com mais de $20 \%$ de eritrócitos com deficiência completa de CD55 e CD59 invariavelmente apre- sentam hemólise. Pacientes com mais de $10 \%$ de neutrófilos CD55 e CD59 negativos possuem risco aumentado de trombose. ${ }^{23}$

Nas formas de SMD sem aumento de blastos e na anemia aplásica, a presença de células tipo HPN indica melhor prognóstico, com menos chance de progressão para LMA no caso da SMD e tendência de resposta favorável à terapia imunossupressora nas duas condições. ${ }^{24}$ De fato, o aumento de células tipo HPN nestas condições parece ser secundário a uma capacidade dessas células de escapar à destruição imune mediada pela doença. ${ }^{25}$

\section{Imunofenotipagem por Citometria de Fluxo (CMF) em condições associadas à linfocitose}

Neoplasias de células linfoides maduras com frequência são causas de linfocitose. Essas doenças incluem as leucemias linfoides crônicas e os linfomas não Hodgkin. Pela identificação de antígenos associados à linhagem, as neoplasias de células linfoides maduras podem ser divididas em neoplasias da linhagem B, T ou NK. ${ }^{3}$

A Tabela 4 apresenta a classificação das doenças linfoides crônicas que podem apresentar-se com células circulantes passíveis de caracterização imunofenotípica por CMF.

\section{Neoplasias linfoides maduras da linhagem B}

A CMF permite identificar células com imunofenótipo anormal dentro da população de células maduras da linhagem B. Existem duas evidências a favor da presença de doença neoplásica que são pesquisadas neste contexto: a monoclonalidade para a cadeia leve da imunoglobulina de superfície (ou kappa ou lambda) e aberrâncias de expressão antigênica relacionadas com doenças específicas.

Neoplasias da linhagem B habitualmente representam um único clone derivado de uma célula com IgS ou kappa ou lambda. Esse fato está em contraste com o padrão policlonal que ocorre na extensa maioria dos casos de linfocitose reativa.

Tabela 4. Classificação das leucemias linfóides crônicas, segundo a linhagem celular de origem

\begin{tabular}{lc}
\hline \multicolumn{1}{c}{ Células B } & \multicolumn{1}{c}{ Células T ou NK } \\
\hline $\begin{array}{l}\text { Leucemia linfocítica crônica } \\
\text { Leucemia prolinfocítica }\end{array}$ & Leucemia prolinfocitica \\
$\begin{array}{l}\text { Tricoleucemia } \\
\text { Clássica }\end{array}$ & Clássica \\
Variante & Voença linfoproliferativa de linfócitos granulares \\
Linfomas não-Hodgkin em fase leucêmica & Células T \\
Linfoma esplênico de linfócitos vilosos & Células NK \\
Linfomas foliculares & Sindrome de Sézary \\
Linfoma linfoplasmocitóide/ Imunocitoma & Leucemia-linfoma de células T do adulto \\
Linfoma de células do manto & Linfomas T - periféricos \\
Outros &
\end{tabular}

Esta tabela é uma reprodução autorizada pelo autor, de "Hematologia: Fundamentos e Prática." Capitulo 51. Autor: Falcäo RP. 
No entanto, embora a detecção de populações monoclonais para cadeia leve seja extensamente usada como sinônimo de neoplasia, é necessária uma avaliação cuidadosa. Existem relatos raros desse achado em populações linfocitárias reativas. Exemplos são a doença de Castleman ${ }^{26}$ e a hiperplasia folicular florida associada ao HIV. ${ }^{27}$ Portanto, os resultados da CMF devem sempre ser interpretados em conjunto com a avaliação clínica, morfológica e, em alguns casos, a análise genotípica. Por outro lado, a avaliação simples da razão kappa/lambda pode ser pouco sensível para a detecção de populações clonais pequenas em amostras que contenham populações reativas policlonais. Uma abordagem capaz de superar essa dificuldade é restringir a análise da clonalidade de IgS a uma determinada população celular com caracte- rísticas de imunofenótipo específico. Esse tipo de abordagem torna-se crucial na avaliação de amostras com suspeita de neoplasia com grande número de células reativas na amostra; um exemplo típico são os linfomas da zona marginal. Por outro lado, a presença de IgS afasta o diagnóstico de doença blástica como a LLA e o linfoma linfoblástico B mediastinal, bem como as doenças plasmocitárias. ${ }^{2}$

A presença de baixa expressão conjunta de IgS e outras moléculas relacionadas ao receptor de membrana de célula B, como o CD20, CD22 e CD79b, é um achado sugestivo de LLC, embora correlação com a morfologia, apresentação clínica e, por vezes, citogenética seja importante para o diagnóstico diferencial com o linfoma difuso de grandes células $\mathrm{B}$ (LDGCB) e com a leucemia prolinfocítica (LP). ${ }^{28}$

Tabela 5. Abordagem de Citometria de Fluxo para o diagnóstico e classificação das neoplasias linfóides B maduras

\begin{tabular}{|c|c|c|}
\hline DOENÇAS A CONSIDERAR & ACHADOS FENOTIPICOS PECULIARES & INFORMAÇOES DIAGNÓSTICAS ADICIONAIS \\
\hline \multicolumn{3}{|l|}{ CD5+ / CD10- } \\
\hline Leucemia linfóide crônica (LLC) & $\begin{array}{l}\text { Fenótipo típico: CD20(+fr), CD22(+fr), Igs(+fr), } \\
\text { CD23+, FMC7- }\end{array}$ & Morfologia caracteristica \\
\hline Linfoma do manto (LM) & $\begin{array}{l}\text { Fenótipo variável; comumente CD20(+fo), Igs(+fo), } \\
\text { CD23+/-, FMC7+/- }\end{array}$ & Ciclina D1+ (IHQ), t(11;14), rearranjo envolve CCND \\
\hline Leucemia Prolinfocítica & $\begin{array}{l}\text { Fenótipo variável pode sobrepor com LLC ou LM; } \\
\text { CD20(+fo), Igs(+fo), CD23+/-, FMC7+/-, CD5+/- }\end{array}$ & Células grandes com nucléolo proeminente \\
\hline Linfoma B da zona marginal & $\begin{array}{l}\text { Fenótipo variável; CD23-, CD11C+/-, CD103+/- } \\
\text { não típico de LCP, comum Igc apenas }\end{array}$ & $\begin{array}{l}\text { Grescimento dentro e peri-foliculos, pode haver } \\
\text { diferenciação plasmocitária. } t(11 ; 18), t(1 ; 14), t(14 ; 18) \\
\text { / rearranjo envolve MALT-1 }\end{array}$ \\
\hline Linfoma difuso de grandes células B & Fenótipo variável & $\begin{array}{l}\text { Células grandes, padrão de crescimento difuso; } \\
\text { considerar transformação de Richter de LLC ou LM }\end{array}$ \\
\hline Linfoma linfoplasmacitico & $\begin{array}{l}\text { Fenótipo não tipico de LCC, } \\
\text { comumente CD23+frl-, lgc+, lgs+/- }\end{array}$ & $\begin{array}{l}\text { Células pequenas, envolvimento primário da } \mathrm{MO} \text { e } \\
\text { sangue periférico }\end{array}$ \\
\hline \multicolumn{3}{|l|}{ CD5- / CD10+ } \\
\hline Linfoma folicular & Comumente bcl2+, CD43- & $\begin{array}{l}\text { Crescimento de padrão folicular, } t(14 ; 18) \text { / rearranjo } \\
\text { envolve } B C L 2\end{array}$ \\
\hline Linfoma difuso de grandes células B & Fenótipo variável, bcl2+l-, CD43+l- & Células grandes, padrão de crescimento difuso \\
\hline Linfoma de Burkitt & Comumente bcl2-, CD10(+fo), CD43+ & $\begin{array}{l}\text { Células uniformes de tamanho intermediánio, rearranjo } \\
\text { envolve } \mathrm{MYC}, \mathrm{Ki}-67+100 \%\end{array}$ \\
\hline Leucemia de células pilosas (LCP) & $\begin{array}{l}\text { Fenótipo típico: CD20(+fo), CD22(+fo), } \\
\text { CD11c(+fo), CD103(+), CD25(+), CD123(+), Igs(+) }\end{array}$ & Morfologia característica; Anexina A1+ \\
\hline \multicolumn{3}{|l|}{ CD5+ / CD10+ } \\
\hline Linfoma folicular & Comumente bcl2+, CD43- & $\begin{array}{l}\text { Crescimento de padrão folicular, } \mathrm{t}(14 ; 18) \text { / rearranjo } \\
\text { envolve } \mathrm{BCL} 2\end{array}$ \\
\hline Linfoma difuso de grandes células B & Fenótipo variável, bcl2+/-, CD43+/- & Células grandes, padrão de crescimento difuso \\
\hline Linfoma do manto (LM) & $\begin{array}{l}\text { Fenótipo variável; comumente CD20(+fo), } \\
\text { Igs(+fo), CD23+/-, FMC7+/- }\end{array}$ & Ciclina D1+ (IHQ), t(11;14), rearranjo envolve CCND \\
\hline Linfoma de Burkitt & Comumente bcl2-, CD10(+fo), CD43+ & $\begin{array}{l}\text { Células uniformes de tamanho intermediário, rearranjo } \\
\text { envolve MYC, } \mathrm{Ki}-67+100 \%\end{array}$ \\
\hline \multicolumn{3}{|l|}{ CD5- / CD10- } \\
\hline Leucemia de células pilosas (LCP) & $\begin{array}{l}\text { Fenótipo típico: CD20(+fo), CD22(+fo), } \\
\text { CD11c(+fo), CD103(+), CD25(+), CD123(+), Igs(+) }\end{array}$ & Morfologia caracteristica; Anexina A1+ \\
\hline Linfoma B da zona marginal & $\begin{array}{l}\text { Fenótipo variável; CD23-, CD11c+/-, } \\
\text { CD103+/- não típico de LCP, comum Igc apenas }\end{array}$ & $\begin{array}{l}\text { Crescimento dentro e perifoliculos, pode haver } \\
\text { diferenciação plasmocitária. } \mathrm{t}(11 ; 18), \mathrm{t}(1 ; 14), \mathrm{t}(14 ; 18) \text { / } \\
\text { rearranjo envolve MALT-1 }\end{array}$ \\
\hline Linfoma difuso de grandes células B & Fenótipo variável, bcl2+l-, CD43+/- & Células grandes, padrāo de crescimento difuso \\
\hline Linfoma folicular CD10- & Fenótipo variável & $\begin{array}{l}\text { Crescimento de padrão folicular, } t(14 ; 18) / \text { rearranjo } \\
\text { envolve } B C L 2\end{array}$ \\
\hline Linfoma do manto CD5- & Fenótipo variável & Ciclina D1+ (IHQ), t(11;14), rearranjo envolve CCND \\
\hline
\end{tabular}

+ indica comumente positivo; comumente negativo; +/ pode ser positivo ou negativo; (fr) intensidade fraca; (fo) intensidade forte; (i) intensidade intermediária; Igs, imunoglobulina de superfície; Igc, imunoglobulina citoplasmática. Tabela traduzida integralmente de Craig e Foon2.

"This research was originally published in Blood. Authors Fiona E. Craig and Kenneth A. Foon. Title:Flow cytometry immunophenotyping for hematologic neoplasms. Blood. 2008, 111; 3941-3967.(C) Americam Society of Hematology" 
Tabela 6. Abordagem por Citometria de Fluxo para o diagnóstico e classificação das neoplasias T maduras

\begin{tabular}{|c|c|c|}
\hline DOENÇAS A CONSIDERAR & ACHADOS FENOTIPICOS PECULIARES & INFORMAÇOES DIAGNOSTICAS ADICIONAIS \\
\hline \multicolumn{3}{|l|}{ CD4+ CD8- } \\
\hline Sindrome de Sezary & $\begin{array}{l}\text { Geralmente CD7-, CD26-, CD25+l- } \\
\text { (com intensidade de fluorescencia heterogênea). }\end{array}$ & $\begin{array}{l}\text { Morfologia e apresentação clínica caracteristicas. } \\
\text { HYLV-1 negativo }\end{array}$ \\
\hline Leucemia Prolinfocitica-T & $\begin{array}{l}\text { Usualmente não tem aberrância fenotípica. } \\
\text { CD16-, CD56- CD57-. }\end{array}$ & $\begin{array}{l}80 \% \mathrm{t}(14 ; 14)(\mathrm{q} 11 ; \mathrm{q} 32) \text { ou inv }(14)(\mathrm{q} 11 ; \mathrm{q} 32) \\
\text { superexpressão protéica de } \mathrm{TCL} 1 .\end{array}$ \\
\hline Leucemia/linfoma $\mathrm{T}$ do adulto & CD7-, CD25+ (intensidade forte e uniforme). & HTLV-1+, endêmico no Japão e Caribe. \\
\hline Linfoma T anaplástico de células grandes & $\begin{array}{l}\text { Geralmente perda de muitos antigenos celulares pan-T. } \\
\text { CD } 30+\text { (forte e uniforme). Proteina Alk-1+l-, CD56+l-, } \\
\text { CD13+l-, CD15+l-, CD } 33+/- \text {. } \\
\text { Proteina citotóxica associado a grânulo(+). }\end{array}$ & $\begin{array}{l}\text { Morfologia anaplástica, com exceção da } \\
\text { variante de células pequenas/monomórficas. } \\
\text { Rearranjo envolve o gene } A L K \text {. }\end{array}$ \\
\hline Linfoma T angioimunoblástico & $\begin{array}{l}\text { Geralmente fenótipo aberrante } \\
\text { (ex. diminuiçāo da intensidade } \mathrm{CD} 7 \text { e CD3) CD10+/. }\end{array}$ & $\begin{array}{l}\text { Morfologia característica. } \mathrm{CXCL} 13+\text {, } \\
\text { células B EBV+ esparsas. }\end{array}$ \\
\hline Linfoma T periférico não especificado & $\begin{array}{l}\text { Fenótipo variado, geralmente perda aberrante do } \\
\text { CD5 e/ou CD7. }\end{array}$ & Diagnóstico por exclusão de outras doenças distintas. \\
\hline \multicolumn{3}{|l|}{ CD4-/CD8+ } \\
\hline $\begin{array}{l}\text { Leucemia linfocitica granular de células } \\
\text { grandes - } T\end{array}$ & $\begin{array}{l}\text { Frequência de expressão aberrante CD5 e/ou CD7. } \\
\text { CD16+l-, CD56+l-, CD57+. TIA-1+, granzima-B+, } \\
\text { perforina+. }\end{array}$ & $\begin{array}{l}\text { Morfologia caracteristica. Usualmente curso } \\
\text { indolente, associado com artrite reumatoide e } \\
\text { citopenias. EBV- }\end{array}$ \\
\hline Linfoma T tipo paniculite subcutânea & $\begin{array}{l}\text { Usualmente com foco CD } 56, \text { EBV-, TCR } \alpha / \beta, \text { TIA-1+, } \\
\text { granzima-B+, perforina+. }\end{array}$ & $\begin{array}{l}\text { Morfologia carcteristica. Diagnóstico diferencial } \\
\text { com lupus profundus }\end{array}$ \\
\hline Linfoma $T$ hepatoesplênico & $\begin{array}{l}\text { Usualmente CD5 - e CD7+, CD16+l-, CD56+, } \\
\text { CD57-, TIA-1+, granzima-B-, perforina-. }\end{array}$ & $\begin{array}{l}\text { Geralmente TCR } \gamma / \delta \text { mas pode ser TCR } \alpha / \beta \text {, EBV- } \\
\text { Frequentemente isocromossomo } 7 q \text {. Usualmente } \\
\text { curso clinico agressivo }\end{array}$ \\
\hline
\end{tabular}

\section{$\mathrm{CD} 4+/ \mathrm{CD} 8+$ \\ Leucemia Prolinfocitica-T \\ Linfoma/ leucemia T do adulto \\ Linfoma T periférico não especificado \\ Usualmente perda significante do fenótipo aberrante. CD16-, CD56-, CD57-. \\ CD7-, CD25+ (sinal uniforme). \\ Fenótipo variável, geralmente perda aberrante do CD5 e/ou CD7.}

$80 \% \mathrm{t}(14 ; 14)(q 11 ; q 32)$. Proteina TCL1 superexpressa

HTLV-1+ endêmico do Japão e Caribe

Diagnóstico por exclusão de outras doenças distintas.

\section{CD4-/CD8 -}

Linfoma T associado à enteropatia

Linfoma $T$ hepatoesplênico

Linfoma $T \gamma / \delta$ não hepatoesplênico
CD5-, CD3+, CD7+, CD103+, CD56+/-, TIA-1+, granzima- $\mathrm{B}+$, perforina+.

Usualmente CD5 - e CD7+, CD16+/-, CD56+, CD57-

TIA-1+, granzima-B-, perforina-.

CD5-, CD56+, maioria CD57-, TCR $/ 8$. TIA-1+, granzima-B+, perforina+.
CD30+l-, EBV-. FISH para ganhos 9q33-34. História de doença celíaca

Geralmente $\mathrm{TCR} \gamma / \delta$ mas pode ser TCR $\alpha / \beta$, EBV-

Frequentemente isocromosomo 7q. Usualmente curso clínico agressivo.

Pele, mucosas e outros sitios extranodais.

EBV frequentemente positivo nas mucosas e negativo nos infiltrados cutâneos.

+ indica comumente positivo; - comumente negativo; +/- pode ser positivo ou negativo. Tabela traduzida integralmente de Craig e Foon ${ }^{2}$

"This research was originally published in Blood. Authors Fiona E. Craig and Kenneth A. Foon. Title:Flow cytometry immunophenotyping for hematologic neoplasms.

Blood. 2008, 111; 3941-3967. (C) Americam Society of Hematology"

A expressão aberrante de antígenos mieloides como o CD13 ou o CD33, embora seja um evento relativamente frequente na LLA, não ocorre com frequência nas neoplasias B maduras. ${ }^{29}$

A presença do marcador CD5 não configura com propriedade uma aberração fenotípica, visto que uma pequena porcentagem de linfócitos B normais apresenta expressão desse marcador (especialmente linfócitos B do sangue periférico)..$^{30}$ População normal CD5 positiva também ocorre na medula óssea. ${ }^{31}$ Ademais, células B CD5 positivas podem ser encontradas em linfonodos, especialmente em pacientes com doença autoimune. ${ }^{32}$ Portanto, a interpretação da expressão de CD5 em populações de células B depende da avaliação conjunta de outros marcadores imunofenotípicos como o CD20, CD22, CD79b e a análise de monoclonalidade de IgS, bem como avaliação clinica e correlação com o mielograma e a BMO.
A CMF fornece informação importante para a classificação das neoplasias maduras de células B pela avaliação conjunta dos marcadores CD5 e CD10 além de marcadores adicionais de acordo com o caso. Tabela 5.

Determinados imunofenótipos podem ter implicação no prognóstico, como a presença do $\mathrm{CD} 38,{ }^{33,34}$ ou do marcador ZAP-70 $0^{35}$ na LLC, ambos conferindo pior prognóstico. Porém, é necessário salientar que a pesquisa de ambos os marcadores está cerceada de dificuldades técnicas que não devem ser desconsideradas para a correta interpretação dos resultados. O marcador CD38 frequentemente apresenta uma distribuição bi -modal, com parte das células neoplásicas negativas e parte positiva na mesma amostra, além de apresentar variabilidade de expressão associada a origem da amostra (sangue versus medula óssea) e variabilidade associada ao tratamento. ${ }^{33,34} \mathrm{Da}$ mesma forma, a pesquisa do ZAP-70 apresenta as seguintes dificuldades: mar- 
cação fraca, inespecífica e lábil ${ }^{36,37}$ e ausência de consenso no método para descriminar as células positivas para ZAP70 na LLC. $^{2}$

\section{Neoplasias Linfoides maduras de células T e NK}

A CMF apresenta papel coadjuvante no diagnóstico e classificação das neoplasias linfoides maduras da linhagem $\mathrm{T}$ / NK e ainda existem diversas dificuldades para o seu uso corriqueiro. Em contraste com o que ocorre nas doenças da linhagem B, é difícil identificar imunofenótipos aberrantes para essas neoplasias. ${ }^{38}$ Embora algum progresso tenha se dado quanto à identificação de algumas entidades específicas, as fronteiras que distinguem as diversas doenças ainda estão sendo estabelecidas e muitas neoplasias continuam na categoria de linfoma T periférico não especificado. ${ }^{2}$

Conforme revisado por Craig e Foon, ${ }^{2}$ mais que efetuar um papel decisivo na classificação das neoplasias maduras $\mathrm{T} / \mathrm{NK}$, a CMF pode responder questionamentos específicos que, quando colocados em conjunto com informações clínicas, de morfologia, imuno-histoquímica e citogenética, auxiliam no diagnóstico definitivo. Seguem as perguntas mais frequentes, que podem ser respondidas com a CMF.

As células neoplásicas são células T ou células NK? A presença de positividade no ensaio citométrico para o CD3 é altamente específica de célula T. Já os anticorpos anti-CD3 usados em imuno-histoquímica usualmente detectam apenas o componente epsilon do CD3 que também está presente nas células NK. ${ }^{2}$

Existe expressão dos componentes do receptor de célula T (TCR)? A CMF é o método padrão ouro para determinar se as células expressam a forma $\alpha / \beta$ ou $\gamma / \delta$ do TCR, diagnóstico difícil por imuno-histoquímica (IHQ) pela carência de anticorpos para a forma $\gamma / \delta$. Vale lembrar que os linfomas esplênicos $\gamma / \delta$ apresentam pior prognóstico. ${ }^{39}$

As células apresentam proteínas de grânulos citotóxicos? Tanto a CMF quanto a IHQ representam bons métodos para este fim. A escolha dependerá do material a ser pesquisado. Positividade para granzima-B e perforina indica fenótipo de célula citotóxica ativada. ${ }^{2}$

Existe expressão de CD4, CD8 ou marcadores NK como CD56, CD57 e CD16? A Tabela 6 apresenta uma abordagem diagnóstica por CMF para a classificação das neoplasias linfoides T e NK.

\section{Conclusões}

A CMF está estabelecida como ferramenta importante no diagnóstico hematopatológico. A qualidade da instrumentação melhorou muito nos últimos anos e atualmente a CMF multiparamétrica (com quatro ou mais marcadores na mesma célula) e com análise de um número muito superior de eventos (500.000 a 1 milhão) é possível na rotina dos laboratórios clínicos. Por consequência, a técnica deixou de ser limitada à análise de grandes populações celulares e passou a ter importância crescente na pesquisa de pequenas populações, como na pesquisa de DRM ou de amostras mais complexas. Os consensos realizados, como o Consenso Internacional de Bethesda, ${ }^{4,40,41}$ auxiliam na uniformização de escolha dos painéis de marcadores a serem utilizados e na interpretação dos resultados. A técnica é atualmente mais robusta, mas o diagnóstico hematopatológico permanece dependente, na maior parte dos casos, de informações clínicas, da morfologia celular no mielograma e BMO e da avaliação genética.

\section{Abstract}

The use of flow cytometry for immunophenotyping is currently an essential tool in the diagnosis of hematological abnormalities. In recent years, new equipment, antibodies, fluorochromes and computer programs have become available. As a result, a better understanding of the pathogeneses of hematological malignancies has emerged and new markers with diagnostic and prognostic relevance have been described. Here we review how this new technology may contribute to the differential diagnosis of patients with bi- or pancytopenia and of lymphocytosis. The common findings as well as the difficulties in interpreting the results obtained by flow cytometry will be discussed. The importance of the concomitant analyses by different methods is also demonstrated. Rev. Bras. Hematol. Hemoter.

Key words: Immunophenotyping; pancytopenia; lymphocytosis; cytometry.

\section{Referências Bibliográficas}

1. Dunphy CH. Applications of flow cytometry and immunohistochemistry to diagnostic hematopathology. Arch Pathol Lab Med. 2004;128(9):1004-22.

2. Craig FE, Foon KA. Craig FE, Foon KA. Flow cytometric immunophenotyping for hematologic neoplasms. Blood. 2008; 111(8):3941-67.

3. Swerdlow SH, Campo E, Harris NL, Jaffe ES, Pileri SA, Stein H, et al. World Health Organization (WHO) Classification of Tumours of Haematopoietic and Lymhoid Tissues. 2008, WHO PRESSIARC; Lyon.

4. Davis BH, Holden JT, Bene MC, Borowitz MJ, Braylan RC, Cornfield $\mathrm{D}$, et al. 2006 Bethesda International Consensus recommendations on the flow cytometric immunophenotypic analysis of hematolymphoid neoplasia: medical indications. Cytometry B Clin Cytom. 2007;72 Suppl 1:S5-13.

5. Orazi A. Histopathology in the diagnosis and classification of acute myeloid leukemia, myelodysplastic syndromes, and myelodysplastic/myeloproliferative diseases. Pathobiology. 2007;74 (2): 97-114.

6. Newell JO, Cessna MH, Greenwood J, Hartung L, Bahler DW. Importance of CD117 in the evaluation of acute leukemias by flow cytometry. Cytometry B Clin Cytom. 2003;52(1):40-3.

7. Arber DA. Realistic pathologic classification of acute myeloid leukemias. Am J Clin Pathol. 2001;115(4):552-60. 
8. Donnenberg AD, Donnenberg VS. Rare-event analysis in flow cytometry. Clin Lab Med. 2007;27(3):627-52, viii.

9. Dworzak MN, Panzer-Grümayer ER. Flow cytometric detection of minimal residual disease in acute lymphoblastic leukemia. Leuk Lymphoma. 2003;44(9):1445-55

10. Campana D. Minimal residual disease in acute lymphoblastic leukemia. Semin Hematol. 2009;46(1):100-6.

11. Campana D. Status of minimal residual disease testing in childhood haematological malignancies. Br J Haematol. 2008;143 (4):481-9.

12. Al-Mawali A, Gillis D, Lewis I. The role of multiparameter flow cytometry for detection of minimal residual disease in acute myeloid leukemia. Am J Clin Pathol. 2009 Jan;131(1):16-26.

13. Tallman MS, Hakiman D, Peterson LC. Hairy Cell Leukemia, In: Hematology: Basic Principles and Practice; Editors: Hoffman R, Furie B, Benz EJ, McGlave P, Silberstein LE, Shattil S. 3 ed, Churchill Livingstone, 1999; 1364-72.

14. Sharpe RW, Bethel KJ. Hairy cell leukemia: diagnostic pathology Hematol Oncol Clin North Am. 2006;20(5):1023-49.

15. Falcão RP. Tricoleucemia (Leucemia de Células Pilosas), In: Hematologia: Fundamentos e Prática; Editors: Zago MA, Falcão RP, Pasquini R. Atheneu 2001; 583-87.

16. Sausville JE, Salloum RG, Sorbara L, Kingma DW, Raffeld M, Kreitman RJ, et al. Minimal residual disease detection in hairy cell leukemia. Comparison of flow cytometric immunophenotyping with clonal analysis using consensus primer polymerase chain reaction for the heavy chain gene. Am J Clin Pathol. 2003;119 (2):213-7.

17. van Bockstaele DR, Berneman ZN, Peetermans ME. Flow cytometric analysis of hairy cell leukemia using right-angle light scatter. Cytometry. 1986;7(2):217-20.

18. Jasionowski TM, Hartung L, Greenwood JH, Perkins SL, Bahler DW. Analysis of CD10+ hairy cell leukemia. Am J Clin Pathol. 2003;120(2):228-35.

19. Robbins BA, Ellison DJ, Spinosa JC, Carey CA, Lukes RJ, Poppema $\mathrm{S}$, et al. Diagnostic application of two-color flow cytometry in 161 cases of hairy cell leukemia. Blood. 1993;82(4):1277-87.

20. Matutes E, Morilla R, Owusu-Ankomah K, Houliham A, Meeus P, Catovsky D. The immunophenotype of hairy cell leukemia (HCL). Proposal for a scoring system to distinguish HCL from B-cell disorders with hairy or villous lymphocytes. Leuk Lymphoma. 1994;14 Suppl 1:57-61.

21. Pagnucco G, Giambanco C, Gervasi F. The role of flow cytometric immunophenotyping in myelodysplastic syndromes. Ann N Y Acad Sci. 2006;1089:383-94.

22. van de Loosdrecht AA, Westers TM, Westra AH, Dräger AM, van der Velden VH, Ossenkoppele GJ. Identification of distinct prognostic subgroups in low- and inBlood. 2008;111(3):1067-77.

23. Hall C, Richards S, Hillmen P. Primary prophylaxis with warfarin prevents thrombosis in paroxysmal nocturnal hemoglobinuria (PNH). Blood. 2003;102(10):3587-91.

24. Wang SA, Pozdnyakova O, Jorgensen JL, Medeiros LJ, Stachurski $\mathrm{D}$, Anderson $\mathrm{M}$, et al. Detection of paroxysmal nocturnal hemoglobinuria clones in patients with myelodysplastic syndromes and related bone marrow diseases, with emphasis on diagnostic pitfalls and caveats. Haematologica. 2009;94(1):29-37.

25. Wang H, Chuhjo T, Yasue S, Omine M, Nakao S. Clinical significance of a minor population of paroxysmal nocturnal hemoglobinuriatype cells in bone marrow failure syndrome. Blood. 2002; 100 (12):3897-902.

26. Du MQ, Liu H, Diss TC, Ye H, Hamoudi RA, Dupin N, et al. Kaposi sarcoma-associated herpesvirus infects monotypic (IgM lambda) but polyclonal naive B cells in Castleman disease and associated lymphoproliferative disorders. Blood. 2001;97(7):2130-6.

27. Kussick SJ, Kalnoski M, Braziel RM, Wood BL. Prominent clonal B-cell populations identified by flow cytometry in histologically reactive lymphoid proliferations. Am J Clin Pathol. 2004;121 (4):464-72.

28. Falcão RP. Leucemia Linfoide Crônica, In: Hematologia: Fundamentos e Prática; Editors: Zago MA, Falcão RP, Pasquini R. Atheneu 2001;569-75.

29. Nakase K, Kita K, Shiku H, Tanaka I, Nasu K, Dohy H, et al. Myeloid antigen, CD13, CD14, and/or CD33 expression is restricted to certain lymphoid neoplasms. Am J Clin Pathol. 1996; 105(6):761-8.

30. Dorshkind K. B Cell Development, In: Hematology: Basic Principles and Practice; Editors: Hoffman R, Furie B, Benz EJ, McGlave P, Silberstein LE, Shattil S. 3 ed, Churchill Livingstone, 1999; 80-90.

31. Jelic TM, Raj AB, Jin B, Kurczynski EM, Tolaymat N, Chang HH Expression of CD5 on hematogones in a 7-year-old girl with Shwachman-Diamond syndrome. Pediatr Dev Pathol. 2001;4 (5): 505-11.

32. Shirai T, Hirose S, Okada T, Nishimura H. CD5+ B cells in autoimmune disease and lymphoid malignancy. Clin Immunol Immunopathol. 1991;59(2):173-86

33. Rassenti LZ, Kipps TJ. Clinical utility of assessing ZAP-70 and CD38 in chronic lymphocytic leukemia. Cytometry B Clin Cytom. 2006;70(4):209-13.

34. Hamblin TJ, Orchard JA, Ibbotson RE, Davis Z, Thomas PW, Stevenson FK, et al. CD38 expression and immunoglobulin variable region mutations are independent prognostic variables in chronic lymphocytic leukemia, but CD38 expression may vary during the course of the disease. Blood. 2002;99(3):1023-9.

35. Rassenti LZ, Huynh L, Toy TL, Chen L, Keating MJ, Gribben JG, et al. ZAP-70 compared with immunoglobulin heavy-chain gene mutation status as a predictor of disease progression in chronic lymphocytic leukemia. N Engl J Med. 2004;351(9):893-901.

36. Marti G, Orfao A, Goolsby CL. ZAP70 editorial: a follow-up to the special issue. Cytometry B Clin Cytom. 2007;72(2):94-5.

37. Marti G, Orfao A, Goolsby C. ZAP-70 in CLL: towards standardization of a biomarker for patient management: history of clinical cytometry special issue. Cytometry B Clin Cytom. 2006;70(4):197-200.

38. Cady FM, Morice WG. Flow cytometric assessment of T-cell chronic lymphoproliferative disorders. Clin Lab Med. 2007;27 (3):513-32, vi.

39. Vega F, Medeiros LJ, Gaulard P. Hepatosplenic and other gammadelta T-cell lymphomas. Am J Clin Pathol. 2007;127(6):869-80.

40. Greig B, Oldaker T, Warzynski M, Wood B. 2006 Bethesda International Consensus recommendations on the immunophenotypic analysis of hematolymphoid neoplasia by flow cytometry: recommendations for training and education to perform clinical flow cytometry. Cytometry B Clin Cytom. 2007;72 Suppl 1:S23-33.

41. Wilson WH. International consensus recommendations on the flow cytometric immunophenotypic analysis of hematolymphoid neoplasia. Cytometry B Clin Cytom. 2007;72 Suppl 1:S2.

Avaliação: Editor e dois revisores externos

Conflito de interesse: sem conflito de interesse

Recebido: 20/04/2009

Aceito: 29/07/2009 